\title{
Overexpression of $\operatorname{Reg} 4$, alone or combined with MMP-7 overexpression, is predictive of poor prognosis in colorectal cancer
}

\author{
XINGWU ZHU ${ }^{1}$, YANG HAN ${ }^{1}$, CHENWEI YUAN ${ }^{1}$, WEIWEI TU ${ }^{3}$, GUOQIANG QIU ${ }^{1}$, \\ $\mathrm{SU} \mathrm{LU}^{2}$, HUIJUN LU ${ }^{2}$, ZHIHAI PENG ${ }^{1}$ and CHONGZHI ZHOU ${ }^{1}$ \\ Departments of ${ }^{1}$ General Surgery and ${ }^{2}$ Pathology, Shanghai Jiaotong University Affiliated First People's Hospital, \\ Shanghai 200080; ${ }^{3}$ Department of General Surgery, Shanghai First People's Hospital, \\ Nanjing Medical University, Nanjing, Jiangsu 210029, P.R. China
}

Received August 7, 2014; Accepted September 23, 2014

DOI: 10.3892/or.2014.3559

\begin{abstract}
Regenerating islet-derived family, member 4 (Reg4) is a secreted protein that plays a critical role in the development of colorectal cancer (CRC). In the present study, we examined the relationship between Reg4 and matrix metalloproteinase-7 (MMP-7) expression in CRC, particularly with regard to metastasis. RT-qPCR, western blotting, tissue microarray (TMA) and immunohistochemical staining were performed to detect Reg4 and MMP-7 expression in CRC tissues and paired adjacent normal tissues. As compared with normal tissues, most paired colon cancers showed $\mathrm{a} \geq 2$-fold increase in the Reg4 and MMP-7 mRNA levels, which was subsequently validated by the post-transcriptional levels. Immunohistochemical analysis demonstrated that Reg4 was associated with lymph node and distant metastasis, advanced American Joint Committee on Cancer (AJCC) stage, and histologic grade. Further studies showed the correlation between Reg4 and MMP-7 expression was significant in CRC with distant metastasis $(r=0.555$, $\mathrm{P}=0.021)$ and in the lymph-node metastasis samples $(\mathrm{r}=0.557$, $\mathrm{P}<0.001)$. Patients with tumor positivity for the two molecules showed a worse prognosis even after radical surgery $(\mathrm{P}<0.001)$. Multivariate analysis revealed that patients with Reg4- and MMP-7-positive tumors had extremely poor OS (HR 4.63; 95\% CI 2.43-8.81; P<0.001) and DFS (HR 3.88; 95\% CI 2.087.22; $\mathrm{P}<0.001)$. Reg4 expression may be useful in the prediction of colon cancer prognosis when combined with MMP-7.
\end{abstract}

\section{Introduction}

Colorectal cancer (CRC) is one of the most common malignancies worldwide and has become the fifth most common

Correspondence to: Dr Chongzhi Zhou, Department of General Surgery, Shanghai Jiaotong University Affiliated First People's Hospital, 85 Wujin Road, Shanghai 200080, P.R. China

E-mail: cz-zhou@163.com

Key words: Reg4, MMP-7, colorectal cancer, prognosis, metastasis cause of cancer-related mortality in China (1). It is estimated that $>50 \%$ of patients succumbing to CRC had developed distant metastasis. Thus, identifying available biomarkers and determining the mechanism involved in the development of metastasis in CRC is necessary.

The regenerating islet-derived family members (Reg) are a family of genes belonging to the calcium-dependent lectin gene superfamily and a group of secretory proteins that are essential for cell regeneration and proliferation (2). Reg4, which was isolated from a cDNA library of ulcerative colitis (UC) tissues by Hartupee et al (3), is the most recently identified member of the Reg family. It has been reported that Reg4 was markedly overexpressed in several gastrointestinal types of cancer including gastric, colorectal and pancreatic cancer (4-8). In CRC, Oue et al (9) reported that Reg4 expression was associated with histologic grade and metastasis and high serum Reg4 concentrations were found in patients with liver metastasis. Furthermore, in vitro studies suggested the overexpression of Reg4 promoted cancer cell proliferation, migration, anti-apoptosis and resistance to chemoradiotherapy (10-13). However, the mechanism of how Reg4 performing these functions in CRC remains to be elucidated. Recently, it was shown that Reg4 promoted the proliferation and invasiveness of pancreatic cancer cells through upregulation of the expression of matrix metalloproteinase-7 (MMP-7) (14).

MMP-7, also known as matrilysin, is the smallest member of the MMP family, playing an important role in the degradation of extracellular matrix during cancer progression (15). MMP-7 was elevated in several primary types of cancer including CRC and pancreatic carcinoma $(16,17)$. MMP-7 is specifically expressed in epithelial tumor cells and has proteolytic activity against a wide spectrum of substrates such as proteoglycans, type IV collagen, fibronectin, elastin and laminin. In addition to degrading the extracellular matrix, MMP-7 was able to enhance angiogenesis by degrading soluble vascular endothelial growth factor (VEGF) receptor-1 which blocked VEGF access to endothelial cells, potentially promoting the metastasis of colon carcinoma cells by processing a cell surface protein(s) and thereby inducing loose and then tight aggregation of tumor cells $(18,19)$. 
CRC cells treated with the recombinant human Reg4 (rhR4) were found to increase the expression of MMP-7 (20). However, their relationship in CRC tissues is not fully understood. Therefore, quantitative real-time PCR (RT-qPCR), western blot analysis, and immunohistochemistry were applied in the present study to clarify the correlation between Reg4 and MMP-7 in CRC from transcriptional and post-transcriptional levels and their relationship with clinical characteristics. The present study aimed to show that positive Reg4 expression is associated with MMP-7 overexpression in colorectal tumors with metastasis and is a potential prognostic factor when combined with MMP-7 expression.

\section{Materials and methods}

Patients and specimens. Fresh primary cancer tissue and grossly visible paired normal tissue were collected from 40 CRC patients who underwent radical surgery at the Shanghai Jiaotong University Affiliated First People's Hospital. The samples were stored at $-80^{\circ} \mathrm{C}$ for RT-qPCR and western blot analysis. The group contained 22 male and 18 female patients with a median age of 53 (range, 32-75) years. For the immunohistochemical study, a total of 186 patients, who underwent curative surgery for CRC at the Shanghai Jiaotong University Affiliated First People's Hospital, also participated in the present study. The group included 77 males and 109 females with a mean age of 68 (range, 22-95) years at the time of surgery. There were 19 cases at stage I, 76 cases at stage II, 74 cases at stage III, and 17 cases at stage IV according to the American Joint Committee on Cancer (AJCC) staging criteria. The patients overall survival (OS) and disease-free survival (DFS) durations were defined as the interval from initial surgery to death and from initial surgery to clinically or radiologically proven recurrence or metastasis, respectively. No patients received either preoperative chemotherapy or radiotherapy. All the patients signed informed consent according to protocols approved by the Institutional Review Boards of the Shanghai Jiaotong University Affiliated First People's Hospital. Ethics approval for the study was obtained from the Ethics Committee of Shanghai Jiaotong University Affiliated First People's Hospital.

RNA extraction and RT-qPCR. Total RNA was isolated from fresh primary tumors and related normal mucosa of $40 \mathrm{CRC}$ patients according to the manufacturer's instructions (TRIzol; Life Technologies, Grand Island, NY, USA), and then reverse transcribed into complementary DNA using the GeneAmp ${ }^{\circledR}$ PCR System 9700 (Applied Biosystems, New York, NY, USA). Primers used in the present study included: Reg4 sense, 5'-TTG ACTGGGACCACTGGAGA-3' and antisense, 5'-AAGGCAA GCTTCCTCACAGG-3'; MMP-7 sense, 5'-GATGAGGATGA ACGCTGGAC-3' and antisense, 5'-GCTAAATGGAGTGGA GGAACAG-3'; and GAPDH sense, 5'-TCTATAAATTGAGC CCGCAGC-3' and antisense, 5'-CCATGGTGTCTGAGCGA TGT-3'. The amplification protocol used was: $95^{\circ} \mathrm{C}$ for $2 \mathrm{~min}$, and then 40 cycles of $95^{\circ} \mathrm{C}$ for $10 \mathrm{sec}, 60^{\circ} \mathrm{C}$ for $30 \mathrm{sec}$, and $72^{\circ} \mathrm{C}$ for $30 \mathrm{sec}$, with a final extension at $72^{\circ} \mathrm{C}$ for $30 \mathrm{sec}$. Crossing threshold values for individual genes were normalized to GAPDH. Each reaction was performed in triplicate. Changes in the mRNA expression of Reg4 and MMP-7 was calculated as fold-change $\left(2^{-\Delta \Delta \mathrm{Ct}}\right)$ relative to control following the formulae: $\operatorname{Reg} 4 \Delta \mathrm{Ct}=\left(\mathrm{Avg} \cdot \operatorname{Reg} 4 \_\mathrm{Ct}-\mathrm{Avg}\right.$.GAPDH_Ct $)$, $\operatorname{Reg} 4 \Delta \Delta \mathrm{Ct}=(\operatorname{Reg} 4 \Delta \mathrm{Ct}$ _tumor $-\operatorname{Reg} 4 \Delta \mathrm{Ct}$ _non-tumor $)$; MMP-7 $\Delta \mathrm{Ct}=$ (Avg.MMP-7_Ct - Avg.GAPDH_Ct $)$, $\mathrm{MMP}-7 \Delta \Delta \mathrm{Ct}=(\mathrm{MMP}-7 \Delta \mathrm{Ct}$ ttumor $-\mathrm{MMP}-7 \Delta \mathrm{Ct}$ _non-tumor $)$.

Western blot analysis. Total protein was extracted from frozen primary colorectal tumors and adjacent normal tissues of four randomly selected patients using the radio immunoprecipitation assay lysis buffer (50 mM Tris $\mathrm{pH} 7.4,150 \mathrm{mM}$ $\mathrm{NaCl}, 1 \% \mathrm{NP}-40,0.5 \%$ sodium deoxycholate and $0.1 \%$ sodium dodecyl sulphate). Protein concentrations were measured using a BCA protein assay kit (Beyotime Biotechnology Co., Jiangsu, China). Equal amounts of protein were subjected to $15 \%$ sodium dodecyl sulphate-polyacrylamide gels and then transferred onto PVDF membranes according to standard protocols. The membranes were blocked in 5\% fat-free milk solution with $0.1 \%$ Tween-20 for $1 \mathrm{~h}$ at room temperature, followed by incubation with the specific primary antibody including Reg4 (1:1,000; R\&D Systems, Minneapolis, MN, USA), MMP-7 (1:500) and GAPDH (1:1,000) (both from Abcam, Cambridge, MA, USA) overnight at $4^{\circ} \mathrm{C}$. After washing the membranes with TBST three times, the blots were incubated with secondary antibodies conjugated to horseradish peroxidase for $1 \mathrm{~h}$ at room temperature. The bound antibodies were detected by enhanced chemiluminescence following the manufacturer's instructions. The abundance of each protein was determined and normalized against GAPDH expression.

TMA construction. For tissue microarray (TMA) construction, primary tumors and paired normal tissues from 186 patients were retrieved from the Department of Pathology of Shanghai Jiaotong University Affiliated First People's Hospital. Of these samples, 63 samples were paired with lymph-node metastasis. Representative areas of tissues were established and $2.0-\mathrm{mm}$ diameter cores were punched from the paraffin blocks. Two cores from each formalin-fixed, paraffin-embedded primary tumor and matched normal tissue at a distance of at least $2 \mathrm{~cm}$ from the tumor were arrayed. TMAs were constructed using a tissue microarray. The samples were examined by at least two investigators to prevent bias.

Immunohistochemistry. Immunohistochemical staining was performed using the primary antibody against Reg4 (1:100; R\&D Systems) or MMP-7 (1:150; Abcam), followed by incubation with secondary antibody conjugated-HRP (DakoCytomation, Glostrup, Denmark). The slides were counterstained with Mayer's hematoxylin. Two independent investigators scored the positive staining of sections without any knowledge of the patients outcomes (double-blinded). The evaluation was based on the staining intensity and area. The staining intensity was graded as 0 (negative), 1 (weak) and 2 (strong). Staining area was scored as 0 (0\%), 1 (1-25\%), 2 (26-50\%), 3 (51-75\%) and $4(76-100 \%)$ according to the percentage of positively stained cells. The sum of the staining score (intensity and extent) index was designated as: 0-2 (negative), 3-6 (positive) (21).

Statistical analysis. Statistical analysis was performed with SPSS, version 19.0 (SPSS, Inc., Chicago, IL, USA). The 

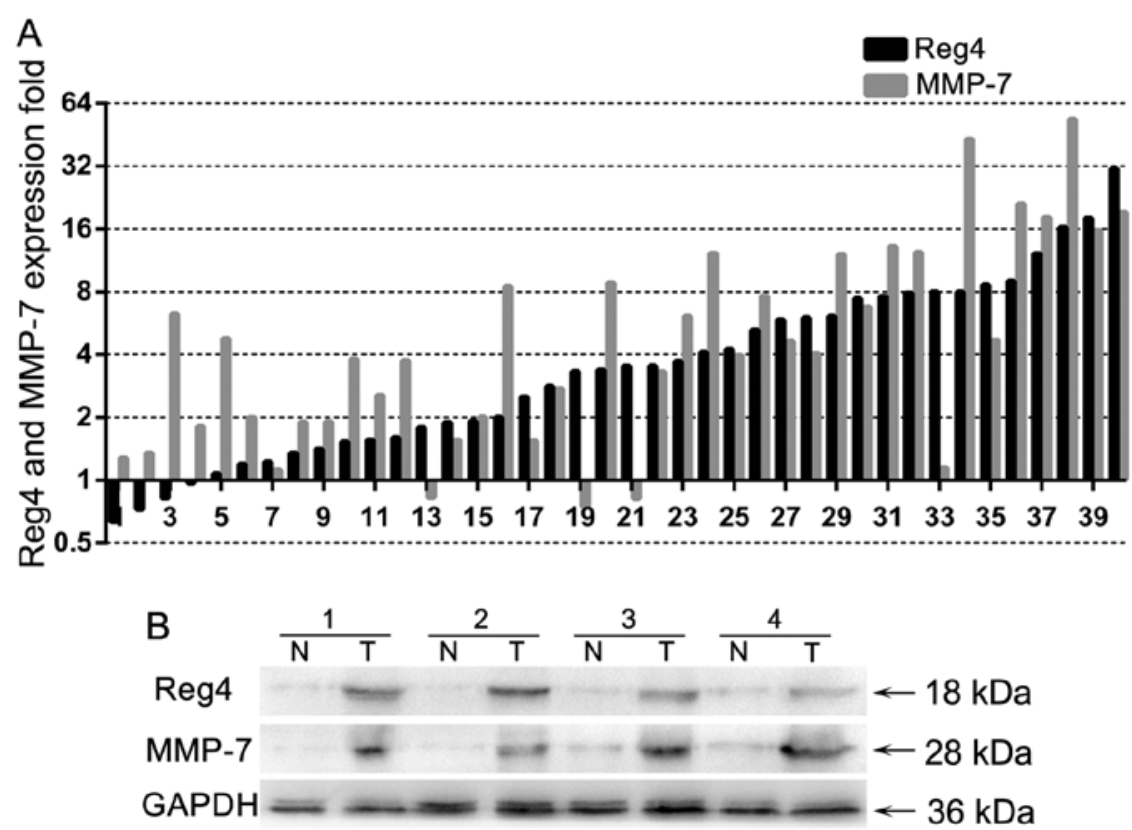

Figure 1. Expression of Reg4 and MMP-7 in normal and cancer tissues. (A) Relative expression of Reg4 and MMP-7 genes in a series of 40 paired colon cancer samples and adjacent normal mucosa were evaluated by RT-qPCR. A logarithmic scale of $2^{-\Delta \Delta C t}$ was used to show the fold change. Twenty-five (62.5\%) colon cancers showed a $\geq 2$-fold increase in Reg4 mRNA levels compared with that of the adjacent non-cancerous tissues, while 27 (67.5\%) colon cancers showed a $\geq 2$-fold increase in MMP-7 mRNA levels. (B) Protein expression in representative four paired colon cancer tissues was measured by western blotting. GAPDH was used as the loading control. The four colon cancer tissues showed a higher Reg4 and MMP-7 expression compared with paired normal mucosa. Reg4, regenerating islet-derived family, member 4; MMP-7, matrix metalloproteinase-7.

differences of mRNA expression of Reg4 or MMP-7 between cancer tissues and paired normal mucosa were calculated by the paired t-test. The two-tailed $\chi^{2}$ or Fisher's exact tests were used where appropriate, to determine the significance of the difference among the covariates. The correlation between Reg4 and MMP-7 protein expression was calculated using Spearman's test. The survival rates were calculated by the Kaplan-Meier method. A log-rank test was used to compare the survival curves. Cox proportional hazard models were used to investigate the independent risk factors for death and significant factors were selected for the final multivariate regression model using the forward LR method. Differences at $\mathrm{P}<0.05$ were considered to indicate a statistically significant result.

\section{Results}

Overexpression of Reg4 and MMP-7 in primary colon cancer compared with adjacent normal mucosa. Of the 40 randomly selected, paired samples subject to RT-qPCR analysis, $25(62.5 \%)$ colon cancers showed a $\geq 2$-fold increase in Reg4 mRNA levels compared with that of the adjacent non-cancerous tissues, while $27(67.5 \%)$ colon cancers showed a $\geq 2$-fold increase in MMP-7 mRNA levels (Fig. 1A). The global expression $(\Delta \mathrm{Ct})$ of $\mathrm{Reg} 4$ or MMP-7 was $6.67 \pm 1.65$ or $9.13 \pm 1.35$ in tumor tissues and $4.93 \pm 1.85(\mathrm{P}<0.001)$ or $7.01 \pm 2.15(\mathrm{P}<0.001)$ in normal tissues, respectively. There were 21 (55\%) colorectal cancer tissues showing an increase in Reg4 and MMP-7 mRNA levels and a statistical correlation of mRNA levels between Reg4 and MMP-7 was performed ( $\mathrm{r}=0.595, \mathrm{P}<0.001)$. Four paired samples were randomly selected to evaluate their protein expression by western blot analysis and the majority of the samples showed higher levels of Reg4 and MMP-7 protein than that of the adjacent non-cancer tissues (Fig. 1B). The results suggested that Reg4 and MMP-7 were elevated in CRC at the transcriptional and post-transcriptional levels.

Association of Reg4 and MMP-7 expression with clinicopathological parameters. Of the 186 normal mucosa samples on the paired TMA, 168 (90.3\%) cases showed negative Reg4 expression and 177 (95.2\%) showed negative MMP-7 expression while the remaining samples showed weak cytoplasmic staining. By contrast, Reg4 and MMP-7 were prominently expressed in colon cancer tissue specimens with $73(39.2 \%)$ and 87 (46.8\%) cases of positive staining, respectively (Fig. 2). Of the 63 matched samples available for analysis, both of the rates of positive Reg4 and MMP-7 expression in CRC lymph-node metastasis (LNM) cells were higher than that in the primary tumors $(\mathrm{P}=0.024$ and $\mathrm{P}=0.003$, respectively; Table I). These data indicate the overexpression of Reg4 and MMP-7 may correlate with colon tumor metastasis.

Associations of Reg4 and MMP-7 expression with clinicopathological factors are shown in Table II. Increased Reg4 expression was significantly associated with LNM (N stage) $(\mathrm{P}=0.003)$, distant metastasis (M stage) $(\mathrm{P}=0.005)$, AJCC stage $(\mathrm{P}=0.004)$ and differentiation $(\mathrm{P}<0.001)$. No correlations were found between Reg4 expression and age, gender, $\mathrm{T}$ stage, tumor location or vascular invasion. The overexpression of MMP-7 was significantly associated with the depth of tumor invasion (T stage) $(\mathrm{P}=0.013), \mathrm{LNM}(\mathrm{N}$ stage $)(\mathrm{P}=0.005), \mathrm{AJCC}$ stage $(\mathrm{P}=0.006)$ and $\mathrm{M}$ stage $(\mathrm{P}=0.010)$. No correlations were found between MMP-7 and age, gender, tumor location, vascular invasion or differentiation. Moreover, Reg4 was more frequently detected in samples that stained positively for 


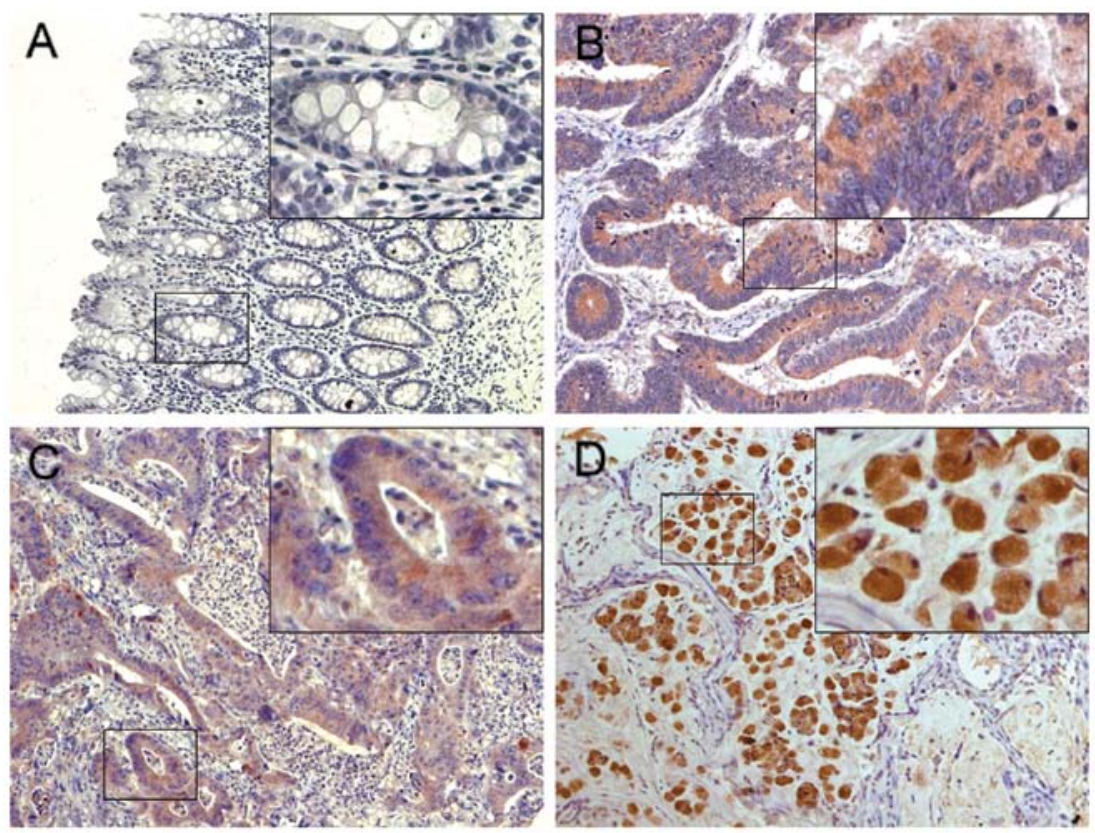

Figure 2. Immunohistochemical staining for Reg4 expression in normal tissue and colon cancer. Representative images of Reg4 expression in normal and colon tumor tissues are shown. (A) Negative Reg4 expression in normal colonic epithelium. (B) Positive Reg4 staining in well-differentiated colon carcinoma, (C) moderately differentiated colon carcinoma and (D) signet ring cell carcinoma. Original magnification, $\mathrm{x} 200$ (x400 for inset images). Reg4, regenerating islet-derived family, member 4.

Table I. Reg4 and MMP-7 immunohistochemical staining for protein expression in normal mucosa, primary tumors and lymph node metastasis.

\begin{tabular}{lccc}
\hline & & Tissue samples & \\
\cline { 2 - 4 } $\begin{array}{l}\text { Expression of Reg4 } \\
\text { or MMP-7 }\end{array}$ & $\begin{array}{c}\text { Normal mucosa } \\
(\mathrm{n}=186)(\%)\end{array}$ & $\begin{array}{c}\text { CRC tissues } \\
(\mathrm{n}=186)(\%)\end{array}$ & $\begin{array}{c}\text { LNM tissues } \\
(\mathrm{n}=63)(\%)\end{array}$ \\
\hline Reg4 & $18(9.7)$ & & $35(55.6)$ \\
Positive & $168(90.3)$ & $113(60.8)$ & $28(44.4)$ \\
Negative & $9(4.8)$ & $87(46.8)$ & $43(68.3)$ \\
MMP-7 & $177(95.2)$ & $99(53.2)$ & $20(31.7)$ \\
Positive & & & $32(50.8)$ \\
Negative & $0(0)$ & $44(23.7)$ & $14(22.2)$ \\
Reg4/MMP-7 & $27(14.5)$ & $72(38.7)$ & $17(27)$ \\
Both positive & $159(85.5)$ & $70(37.6)$ & $<0.001^{\mathrm{b}}$ \\
One positive & & & $<0.001^{\mathrm{c}}$ \\
Both negative & & & $3(39)$ \\
\hline
\end{tabular}

Reg4, regenerating islet-derived family, member 4; MMP-7, matrix metalloproteinase-7; CRC, colorectal cancer; LNM, lymph-node metastasis.

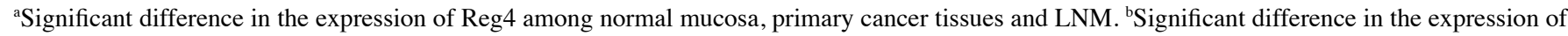
MMP-7 among normal mucosa, primary cancer tissues and LNM. 'Significant difference in the expression of Reg4/MMP-7 among normal mucosa, primary cancer tissues and LNM.

MMP-7 (Fig. 3). Particularly in the tumors with distant metastasis, $24.7 \%$ (11/17) were expressed in Reg4 and MMP-7, and a statistical correlation $(\mathrm{r}=0.555, \mathrm{P}=0.021)$ was observed. Furthermore, we examined the expression of Reg4 and MMP-7 in the metastatic lymph nodes and found the rate of LNM with a positive expression of Reg4 and MMP-7 was higher than that in the normal mucosa and the primary cancer $(\mathrm{P}<0.001)$, and the correlation of the two molecules in the metastatic lymph nodes was statistically significant $(\mathrm{r}=0.557, \mathrm{P}<0.001$; Table I).

Survival analysis and prognostic significance of Reg4 or MMP-7 expression. To assess the possible association between tumor Reg4 or MMP-7 expression and patient survival, the Kaplan-Meier plots with a log-rank test for OS and DFS were 
Table II. Association between clinicopathological characteristics and Reg4 or MMP-7 protein expression.

\begin{tabular}{|c|c|c|c|c|c|c|}
\hline \multirow[b]{2}{*}{ Characteristics } & \multicolumn{2}{|c|}{ Expression of Reg4 } & \multirow[b]{2}{*}{ P-value } & \multicolumn{2}{|c|}{ Expression of MMP-7 } & \multirow[b]{2}{*}{ P-value } \\
\hline & $\begin{array}{c}\text { Positive } \\
(n=73)\end{array}$ & $\begin{array}{c}\text { Negative } \\
(\mathrm{n}=113)\end{array}$ & & $\begin{array}{c}\text { Positive } \\
(\mathrm{n}=87)\end{array}$ & $\begin{array}{c}\text { Negative } \\
(\mathrm{n}=99)\end{array}$ & \\
\hline Age (years) & & & 0.432 & & & 0.746 \\
\hline$<65$ & 32 & 43 & & 34 & 41 & \\
\hline$\geq 65$ & 41 & 70 & & 53 & 58 & \\
\hline Gender & & & 0.198 & & & 0.547 \\
\hline Male & 26 & 51 & & 34 & 43 & \\
\hline Female & 47 & 62 & & 53 & 56 & \\
\hline Location & & & 0.264 & & & 0.589 \\
\hline Right & 35 & 46 & & 42 & 39 & \\
\hline Transverse & 10 & 9 & & 9 & 10 & \\
\hline Descending & 5 & 14 & & 7 & 12 & \\
\hline Sigmoid & 23 & 44 & & 29 & 38 & \\
\hline T stage & & & 0.276 & & & $0.013^{\mathrm{a}}$ \\
\hline $\mathrm{T} 1$ & 3 & 5 & & 2 & 6 & \\
\hline $\mathrm{T} 2$ & 7 & 10 & & 6 & 11 & \\
\hline $\mathrm{T} 3$ & 21 & 48 & & 25 & 44 & \\
\hline $\mathrm{T} 4$ & 42 & 50 & & 54 & 38 & \\
\hline N stage & & & $0.003^{\mathrm{a}}$ & & & $0.005^{\mathrm{a}}$ \\
\hline NO & 30 & 66 & & 34 & 62 & \\
\hline N1 & 22 & 36 & & 33 & 25 & \\
\hline $\mathrm{N} 2$ & 21 & 11 & & 20 & 12 & \\
\hline M stage & & & $0.005^{\mathrm{a}}$ & & & $0.010^{\mathrm{a}}$ \\
\hline M0 & 61 & 108 & & 74 & 95 & \\
\hline M1 & 12 & 5 & & 13 & 4 & \\
\hline AJCC stage & & & $0.004^{\mathrm{a}}$ & & & $0.006^{\mathrm{a}}$ \\
\hline I & 9 & 10 & & 6 & 13 & \\
\hline II & 20 & 56 & & 28 & 48 & \\
\hline III & 32 & 42 & & 40 & 34 & \\
\hline IV & 12 & 5 & & 13 & 4 & \\
\hline Vessel invasion & & & 0.392 & & & 0.172 \\
\hline No & 66 & 106 & & 78 & 94 & \\
\hline Yes & 7 & 7 & & 9 & 5 & \\
\hline Differentiation & & & $<0.001^{\mathrm{a}}$ & & & 0.762 \\
\hline Well & 21 & 65 & & 39 & 47 & \\
\hline Moderate & 32 & 40 & & 36 & 36 & \\
\hline Poor & 20 & 8 & & 12 & 16 & \\
\hline MMP-7 & & & $0.003^{\mathrm{b}}$ & & & \\
\hline Positive & 44 & 43 & & & & \\
\hline Negative & 29 & 70 & & & & \\
\hline
\end{tabular}

${ }^{\mathrm{a}} \mathrm{P}<0.05$ indicates a significant association among the variables based on two-tailed $\chi^{2}$ or Fisher's exact tests. ${ }^{\mathrm{b}}$ The significant difference of the correlation between Reg4 and MMP-7 based on Spearman's test. Reg4, regenerating islet-derived family, member 4; MMP-7, matrix metalloproteinase-7.

undertaken (Fig. 4). It showed that patients with Reg4 overexpression tumors had a poorer OS $(\mathrm{P}<0.001)$ and DFS $(\mathrm{P}<0.001)$ than patients with Reg4-negative tumors (Fig. 4A), and positive MMP-7 expression patients had a lower OS $(\mathrm{P}<0.001)$ and DFS
$(\mathrm{P}<0.001)$ rate than patients with a negative MMP-7 expression (Fig. 4B). Furthermore, with regard to the concomitant expression of Reg4 and MMP-7 proteins, we divided the samples into three groups: group 1, tumors exhibiting no expression of Reg4 


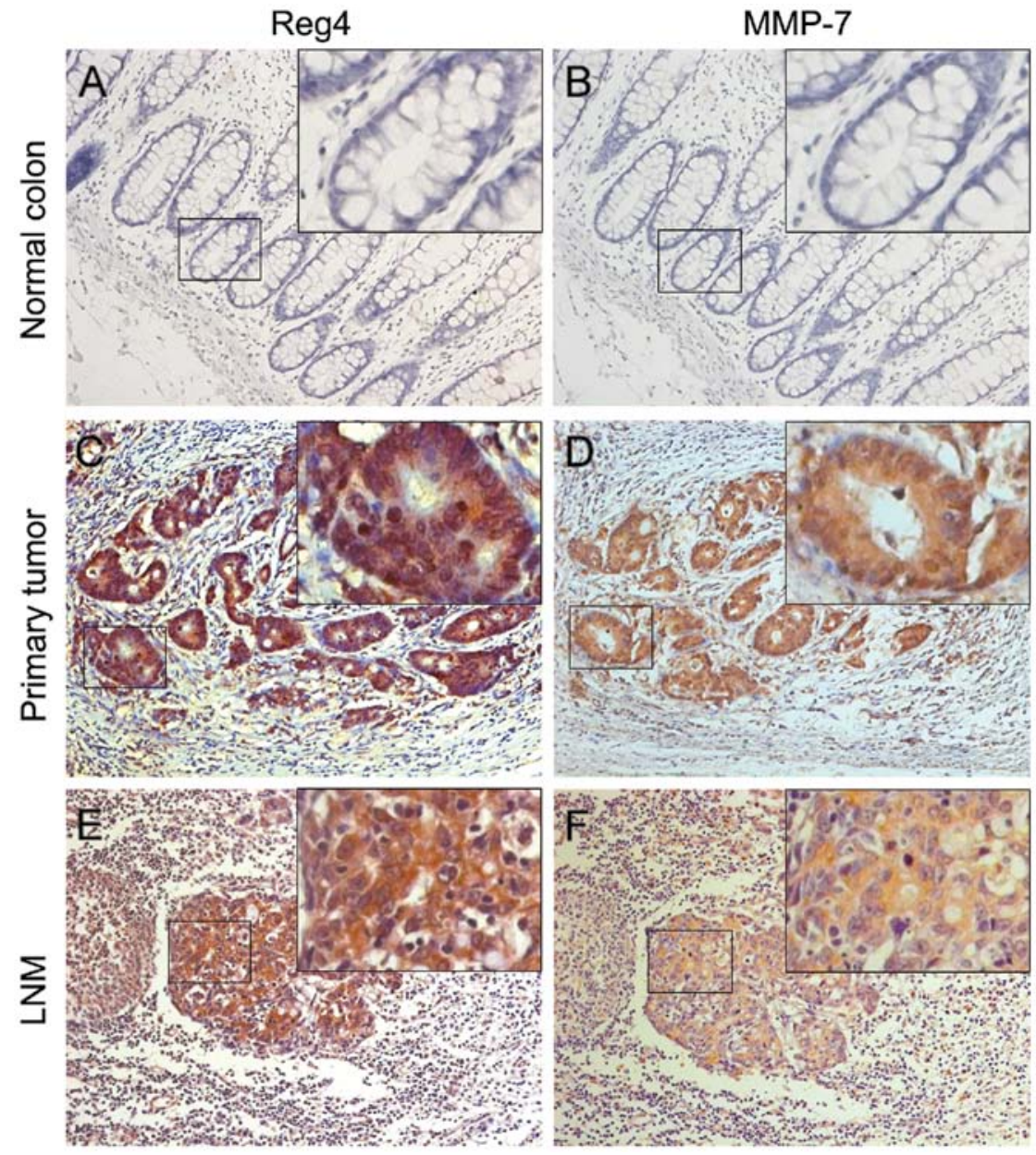

Figure 3. Expression of Reg4 and MMP-7 in normal, cancer and lymph node tissues. (A and B) Negative-Reg4 and MMP-7 staining in normal colon tissue. (C snd D) Positive Reg4 and MMP-7 staining in colon cancer tissue. (E and F) Metastastic lymph node tissue showed positive Reg4 and MMP-7 staining. Original magnification, x200 (x400 for inset images). Reg4, regenerating islet-derived family, member 4; MMP-7, matrix metalloproteinase-7.

and MMP-7 (Reg4-/MMP-7-, 70 specimens); group 2, tumors with abnormal expression of only 1 protein (Reg4/MMP- $7^{+}$or Reg4+/MMP-7-, 72 specimens); group 3, tumors with abnormal expression of the two proteins (Reg $4^{+} / \mathrm{MMP}^{-} 7^{+}, 44$ specimens). Notably, a better OS and DFS in group 1 was observed as compared to group 2, while group 3 showed the worst OS and DFS of the three groups $(\mathrm{P}<0.001)$ (Fig. 4C).

Using a univariate analysis in the Cox proportional hazards model, a decreased OS and increased postoperative recurrence were associated with the depth of tumor invasion, LNM, distant metastasis, AJCC stage, histological differentiation, vessel invasion, Reg4 expression, MMP-7 expression and the expression of Reg4 and MMP-7 (Table III). The multivariate analysis revealed that the expression of Reg4 and MMP-7 was an independent prognostic factor for OS (HR 4.63; 95\% CI 2.43-8.81; $\mathrm{P}<0.001$ ) and DFS (HR 3.88; 95\% CI 2.08-7.22; $\mathrm{P}<0.001$ ), but not the expression of Reg4 or MMP-7 alone.

\section{Discussion}

Reg4 was first found from the proliferating cells in UC which potentially developed into CRC when progression occurred over 10 years. Findings of previous studies showed Reg4 was markedly upregulated in UC and colorectal adenomas although staining in the perinuclear of neuroendocrine cells in normal colon tissues was detected $(4,22,23)$. In the present study, we reported that Reg4 was overexpressed in CRC at the transcriptional and post-transcriptional levels. Further validation by immunohistochemistry showed that $39.2 \%$ of primary CRCs had positive Reg4 protein staining. This is consistent with the results reported by Oue et al (9). This finding suggests that Reg4 has an important role in the progression of CRC carcinogenesis.

In the present study, the correlations between Reg4 expression and clinicopathological characteristics were evaluated. Overexpression of Reg4 was significantly associated with clinical stage, $\mathrm{T}$ stage, lymph node metastasis (LNM) and M stage. These correlations suggest that Reg4 overexpression may promote tumor invasion and metastasis. Moreover, the results show that the rate of positive Reg4 expression in LNM was higher than that in primary tumors, and higher in patients with distant metastasis than in patients without distant metastasis. Therefore, Reg4 may be an effectively diagnostic biomarker of CRC patients with metastasis. However, it is not clear how Reg4 performed its functions of promoting metastasis of colon cancer cells.

Recently, He et al (14) reported that in pancreatic cancer cells, the upregulation of Reg4 may lead to the overexpression of MMP-7, thereby increasing the metastatic ability of cancer cells. MMP-7 is important in the invasion and metastasis of 

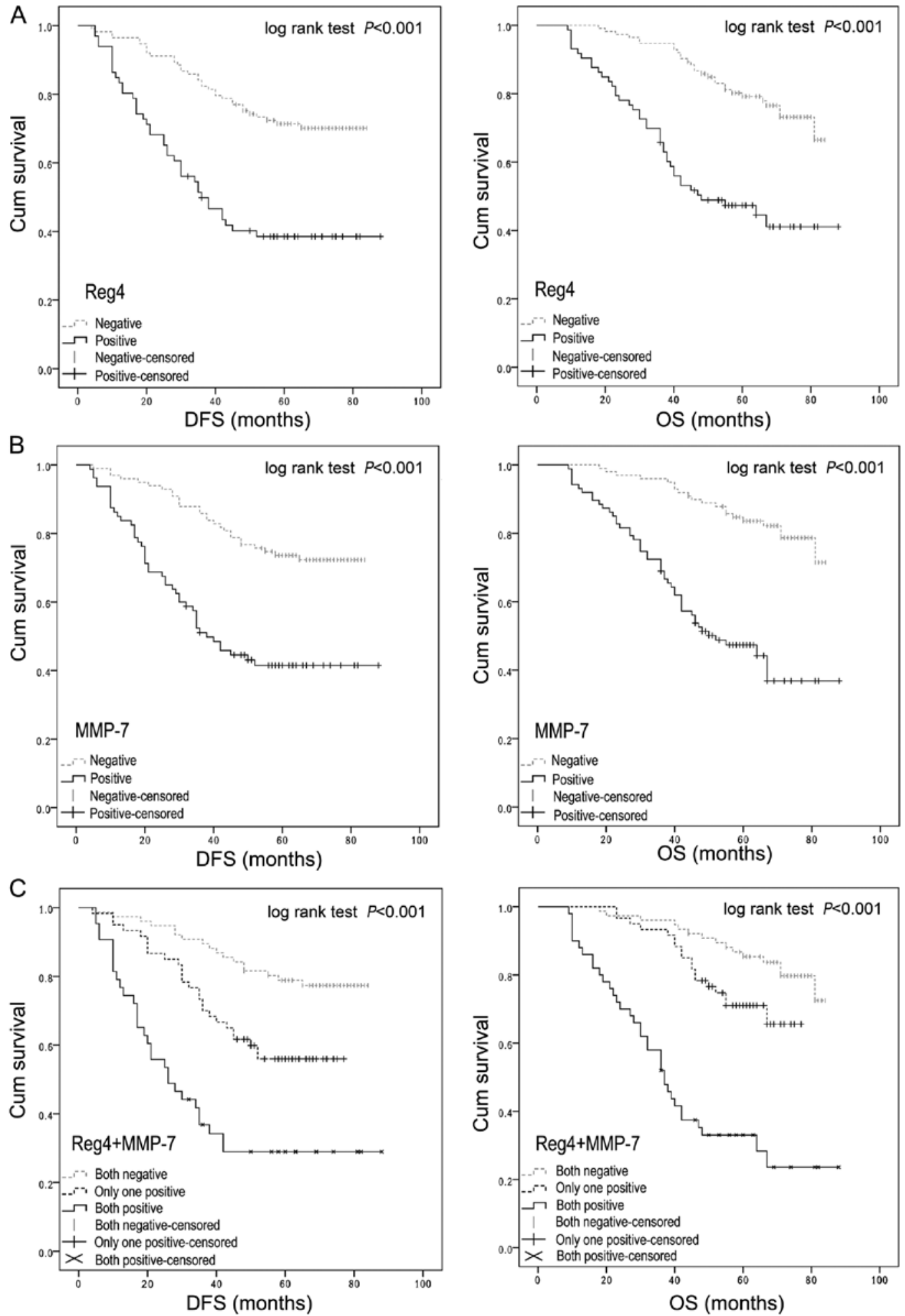

Figure 4. Kaplan-Meier plots of disease-free survival (DFS) and overall survival (OS). (A) DFS and OS of patients in relation to Reg4 expression levels determined by immunohistochemical staining. (B) DFS and OS of patients with negative and positive MMP-7 expression. (C) DFS and OS were significantly lower in patients with Reg4- and MMP-7-positive tumors than in those with Reg4-and MMP-7-negative tumors.

carcinoma cells by cleaving membrane proteins such as integrin $\beta 4$, syndecan- 1 and E-cadherin (24). Thus, we examined the relationship between MMP-7 and clinicopathological characteristics in CRC. In the present study, MMP-7 was more frequently observed in lymph-node metastatic cells than primary tumors and normal colorectal tissue, and it is indicated that MMP-7 may participate in the invasion and metastasis of CRC. Furthermore, a statistically significant positive correlation ( $\mathrm{r}=0.217, \mathrm{P}=0.003)$ between $\mathrm{Reg} 4$ and MMP-7 in CRC was observed. Particularly in LNM, the correlation $(r=0.557, \mathrm{P}<0.001)$ between the two molecules was more significant. These data suggest that MMP-7 may be a biomarker predicting the metastasis of CRC when combined with Reg4. 
Table III. Univariate and multivariate Cox proportional hazard models for overall survival (OS) and disease-free survival (DFS).

\begin{tabular}{|c|c|c|c|c|c|c|c|c|}
\hline \multirow[b]{2}{*}{ Variable } & \multicolumn{4}{|c|}{ OS } & \multicolumn{4}{|c|}{ DFS } \\
\hline & $\begin{array}{c}\text { Univariate } \\
\text { HR }(95 \% \text { CI })\end{array}$ & P-value & $\begin{array}{l}\text { Multivariate } \\
\text { HR }(95 \% \text { CI })\end{array}$ & P-value & $\begin{array}{c}\text { Univariate } \\
\text { HR }(95 \% \mathrm{CI})\end{array}$ & P-value & $\begin{array}{l}\text { Multivariate } \\
\text { HR }(95 \% \text { CI) }\end{array}$ & P-value \\
\hline \multicolumn{9}{|l|}{ Age (years) } \\
\hline$<65$ & 1 & & & & 1 & & & \\
\hline$\geq 65$ & $1.08(0.67-1.76)$ & 0.753 & & & $1.04(0.65-1.67)$ & 0.856 & & \\
\hline \multicolumn{9}{|l|}{ Gender } \\
\hline Male & 1 & & & & 1 & & & \\
\hline Female & $1.52(0.92-2.51)$ & 0.105 & & & $1.21(0.75-1.93)$ & 0.436 & & \\
\hline \multicolumn{9}{|l|}{ Location } \\
\hline Right & 1 & & & & 1 & & & \\
\hline Transverse & $0.82(0.34-1.98)$ & 0.654 & & & $0.83(0.34-2.00)$ & 0.674 & & \\
\hline Left & $1.04(0.46-2.39)$ & 0.923 & & & $0.98(0.43-2.23)$ & 0.954 & & \\
\hline Sigmoid & $1.13(0.67-1.92)$ & 0.645 & & & $1.27(0.76-2.10)$ & 0.362 & & \\
\hline \multicolumn{9}{|l|}{ T stage } \\
\hline $\mathrm{T} 1$ & $0.36(0.09-1.50)$ & 0.161 & & & $0.34(0.08-1.39)$ & 0.133 & $0.30(0.07-1.28)$ & 0.103 \\
\hline $\mathrm{T} 2$ & $0.08(0.01-0.55)$ & $0.011^{\mathrm{a}}$ & & & $0.15(0.04-0.60)$ & $0.007^{\mathrm{a}}$ & $0.26(0.06-1.13)$ & $0.073^{\mathrm{a}}$ \\
\hline $\mathrm{T} 3$ & $0.34(0.20-0.61)$ & $<0.001^{\mathrm{a}}$ & & & $0.44(0.26-0.73)$ & $0.002^{\mathrm{a}}$ & $0.42(0.24-0.73)$ & $0.002^{\mathrm{a}}$ \\
\hline $\mathrm{T} 4$ & 1 & & & & 1 & & 1 & \\
\hline \multicolumn{9}{|l|}{$\mathrm{N}$ stage } \\
\hline No & 1 & & & & 1 & & 1 & \\
\hline N1 & $5.44(2.74-10.82)$ & $<0.001^{\mathrm{a}}$ & & & $3.17(1.78-5.67)$ & $<0.001^{\mathrm{a}}$ & $2.04(1.11-3.75)$ & $0.021^{\mathrm{a}}$ \\
\hline $\mathrm{N} 2$ & $18.85(9.35-38.00)$ & $<0.001^{\mathrm{a}}$ & & & $12.19(6.66-22.33)$ & $<0.001^{\mathrm{a}}$ & $8.27(4.25-16.11)$ & $<0.001^{\mathrm{a}}$ \\
\hline \multicolumn{9}{|l|}{ M stage } \\
\hline M0 & 1 & & & & 1 & & 1 & \\
\hline M1 & $14.12(7.69-25.93)$ & $<0.001^{\mathrm{a}}$ & & & $9.68(4.77-19.68)$ & $<0.001^{\mathrm{a}}$ & $4.61(2.18-9.78)$ & $<0.001^{\mathrm{a}}$ \\
\hline \multicolumn{9}{|l|}{ AJCC stage } \\
\hline I & 1 & & & & 1 & & & \\
\hline II & $2.91(0.38-22.57)$ & 0.306 & & & $2.42(0.56-10.42)$ & 0.236 & & \\
\hline III & $15.74(2.16-114.86)$ & $0.007^{\mathrm{a}}$ & & & $8.59(2.08-35.53)$ & $0.003^{\mathrm{a}}$ & & \\
\hline IV & $110.05(14.30-847.13)$ & $<0.001^{\mathrm{a}}$ & & & $45.28(9.67-211.92)$ & $<0.001^{\mathrm{a}}$ & & \\
\hline \multicolumn{9}{|l|}{ Vessel invasion } \\
\hline No & 1 & & & & 1 & & & \\
\hline Yes & $4.70(2.54-8.70)$ & $<0.001^{\mathrm{a}}$ & & & $4.02(2.10-7.71)$ & $<0.001^{\mathrm{a}}$ & & \\
\hline \multicolumn{9}{|l|}{ Differentiation } \\
\hline Well & 1 & & & & 1 & & & \\
\hline Moderate & $2.54(1.39-4.67)$ & $0.003^{\mathrm{a}}$ & & & $2.43(1.41-4.17)$ & $0.001^{\mathrm{a}}$ & & \\
\hline Poor & $7.51(3.93-14.37)$ & $<0.001^{\mathrm{a}}$ & & & $4.91(2.58-4.76)$ & $<0.001^{\mathrm{a}}$ & & \\
\hline \multicolumn{9}{|l|}{ Reg4 } \\
\hline Negative & 1 & & & & 1 & & & \\
\hline Positive & $3.40(2.08-5.53)$ & $<0.001^{\mathrm{a}}$ & & & $3.00(1.89-4.93)$ & $<0.001^{\mathrm{a}}$ & & \\
\hline \multicolumn{9}{|l|}{ MMP-7 } \\
\hline Negative & 1 & & & & 1 & & & \\
\hline Positive & $4.39(2.58-7.48)$ & $<0.001^{\mathrm{a}}$ & & & $3.05(1.89-4.93)$ & $<0.001^{\mathrm{a}}$ & & \\
\hline \multicolumn{9}{|l|}{ Reg4/MMP-7 } \\
\hline Both negative & 1 & & 1 & & 1 & & 1 & \\
\hline One positive & $1.92(0.96-3.84)$ & 0.066 & $1.55(0.77-3.12)$ & 0.225 & $2.31(1.25-4.27)$ & $0.007^{\mathrm{a}}$ & $2.19(1.17-4.08)$ & $0.014^{\mathrm{a}}$ \\
\hline Both positive & $7.50(4.04-13.92)$ & $<0.001^{\mathrm{a}}$ & $4.63(2.43-8.81)$ & $<0.001^{\mathrm{a}}$ & $5.93(3.25-10.84)$ & $<0.001^{\mathrm{a}}$ & $3.88(2.08-7.22)$ & $<0.001^{\mathrm{a}}$ \\
\hline
\end{tabular}

HR, hazard ratio; CI, confidence interval; AJCC, American Joint Committee on Cancer; Reg4, regenerating islet-derived family, member 4; MMP-7, matrix metalloproteinase-7. ${ }^{\mathrm{P}} \mathrm{P}<0.05$ indicated that $95 \% \mathrm{CI}$ of $\mathrm{HR}$ did not include 1. 
In the present study, the patients with overexpression of Reg4 and MMP-7 had an increased risk of tumor recurrence and shorter survival than patients with a negative expression of Reg4 or MMP-7. Multivariate Cox proportional hazard model showed Reg4 combined with MMP-7 expression is an independent prognostic factor for OS and DFS. Findings of previous studies also suggest that the patients with positive Reg4 or MMP-7 expression had a poor response for chemotherapy and radiotherapy than patients with a negative Reg4 or MMP-7 expression $(12,13,25)$. As mentioned above, Reg4 and MMP-7 may have a strong predictive value and serve as drug targets for CRC patients.

The mechanism of how Reg4 regulates MMP-7 in CRC is not well elucidated. It was reported that MMP-7, which may be considered to function as an oncogene since colorectal tumorigenesis was suppressed in mice lacking MMP-7 (26), was a target gene of the $\beta$-catenin/TCF-4 signaling pathway (27). Bishnupuri el al (28) recently provided evidence that Reg4 regulated CRC cell proliferation and division by the Akt-GSK3 $\beta$ - $\beta$-catenin-TCF-4 signaling pathway. Therefore, Reg4 may promote colorectal tumorigenesis and CRC metastasis by upregulating MMP-7 through the Akt-GSK3 $\beta-\beta$-catenin-TCF-4 signaling pathway.

To the best of our knowledge, this is the first study to report that the expression of Reg4 was correlated with that of MMP-7 in CRC at the transcriptional and post-transcriptional levels. Both Reg4 and MMP-7 were significantly upregulated in CRC and were associated with the invasion and metastasis of tumor cells. We suggest that tumor Reg4 and MMP-7 expression is a clinically useful, prognostic indicator of cancer metastasis, recurrence and poor patient survival. These preliminary findings should be fully verified in CRC cells at the molecular level and in murine models at the animal level.

\section{References}

1. Chen $\mathrm{W}$, Zheng $\mathrm{R}$, Zhang S, et al: Annual report on status of cancer in China, 2010. Chin J Cancer Res 26: 48-58, 2014.

2. Iovanna JL and Dagorn JC: The multifunctional family of secreted proteins containing a C-type lectin-like domain linked to a short N-terminal peptide. Biochim Biophys Acta 1723: 8-18, 2005.

3. Hartupee JC, Zhang H, Bonaldo MF, Soares MB and Dieckgraefe BK: Isolation and characterization of a cDNA encoding a novel member of the human regenerating protein family: Reg IV. Biochim Biophys Acta 16: 287-293, 2001.

4. van Beelen Granlund A, Østvik AE, Brenna Ø, Torp SH, Gustafsson BI and Sandvik AK: REG gene expression in inflamed and healthy colon mucosa explored by in situ hybridisation. Cell Tissue Res 352: 639-646, 2013.

5. Yamagishi H, Fukui H, Sekikawa A, et al: Expression profile of REG family proteins REG I $\alpha$ and REG IV in advanced gastric cancer: comparison with mucin phenotype and prognostic markers. Mod Pathol 22: 906-913, 2009.

6. Numata M, Oshima T, Yoshihara K, et al: Relationship between RegIV gene expression to outcomes in colorectal cancer. J Surg Oncol 104: 205-209, 2011.

7. Wang F, Xu L, Guo C, et al: Identification of RegIV as a novel GLI1 target gene in human pancreatic cancer. PLoS One 6: e18434, 2011 .
8. Yang L, Lan S, Liu J and Yang Z: Expression of MK-1 and RegIV and its clinicopathological significances in the benign and malignant lesions of gallbladder. Diagn Pathol 6: 100, 2011.

9. Oue N, Kuniyasu H, Noguchi T, et al: Serum concentration of Reg IV in patients with colorectal cancer: overexpression and high serum levels of Reg IV are associated with liver metastasis. Oncology 72: 371-380, 2007.

10. Rafa L, Dessein AF, Devisme L, et al: REG4 acts as a mitogenic, motility and pro-invasive factor for colon cancer cells. Int $\mathrm{J}$ Oncol 36: 689-698, 2010.

11. Ying LS, Yu JL, Lu XX and Ling ZQ: Enhanced RegIV expression predicts the intrinsic 5-fluorouracil (5-FU) resistance in advanced gastric cancer. Dig Dis Sci 58: 414-422, 2013.

12. Bishnupuri KS, Luo Q, Sainathan SK, et al: Reg IV regulates normal intestinal and colorectal cancer cell susceptibility to radiation-induced apoptosis. Gastroenterology 138: 616-626, 2010.

13. Mitani Y, Oue N, Matsumura S, et al: Reg IV is a serum biomarker for gastric cancer patients and predicts response to 5-fluorouracil-based chemotherapy. Oncogene 26: 4383-4393, 2007.

14. He XJ, Jiang XT, Ma YY, et al: REG4 contributes to the invasiveness of pancreatic cancer by upregulating $M M P-7$ and $M M P-9$. Cancer Sci 103: 2082-2091, 2012.

15. Rucci N, Sanità P and Angelucci A: Roles of metalloproteases in metastatic niche. Curr Mol Med 11: 609-622, 2011.

16. Yang B, Su K, Gao J and Rao Z: Expression and prognostic value of matrix metalloproteinase-7 in colorectal cancer. Asian Pac J Cancer Prev 13: 1049-1052, 2012.

17. Fukuda A, Wang SC, Morris JP IV, et al: Stat 3 and MMP7 contribute to pancreatic ductal adenocarcinoma initiation and progression. Cancer Cell 19: 441-455, 2011.

18. Ito TK, Ishii G, Saito $S$, et al: Degradation of soluble VEGF receptor-1 by MMP-7 allows VEGF access to endothelial cells. Blood 113: 2363-2369, 2009.

19. Kioi M, Yamamoto K, Higashi S, Koshikawa N, Fujita K and Miyazaki K: Matrilysin (MMP-7) induces homotypic adhesion of human colon cancer cells and enhances their metastatic potential in nude mouse model. Oncogene 22: 8662-8670, 2003.

20. Bishnupuri KS, Luo Q, Murmu N, Houchen CW, Anant S and Dieckgraefe BK: Reg IV activates the epidermal growth factor receptor/Akt/AP-1 signaling pathway in colon adenocarcinomas. Gastroenterology 130: 137-149, 2006.

21. Han Y, Tu WW, Wen YG, et al: Increased expression of TBX2 is a novel independent prognostic biomarker of a worse outcome in colorectal cancer patients after curative surgery and a potential therapeutic target. Med Oncol 30: 688, 2013.

22. Zhang Y, Lai M, Lv B, et al: Overexpression of Reg IV in colorectal adenoma. Cancer Lett 200: 69-76, 2003.

23. Oue N, Mitani Y, Aung PP, et al: Expression and localization of Reg IV in human neoplastic and non-neoplastic tissues: Reg IV expression is associated with intestinal and neuroendocrine differentiation in gastric adenocarcinoma. J Pathol 207: 185-198, 2005.

24. Tsunezumi J, Higashi S and Miyazaki K: Matrilysin (MMP-7) cleaves C-type lectin domain family 3 member A (CLEC3A) on tumor cell surface and modulates its cell adhesion activity. J Cell Biochem 106: 693-702, 2009.

25. Zhang W, Li Y, Yang L, et al: Knockdown of MMP-7 inhibits cell proliferation and enhances sensitivity to 5-fluorouracil and X-ray irradiation in colon cancer cells. Clin Exp Med 14: 99-106, 2014.

26. Wilson CL, Heppner KJ, Labosky PA, Hogan BL and Matrisian LM: Intestinal tumorigenesis is suppressed in mice lacking the metalloproteinase matrilysin. Proc Natl Acad Sci USA 94: 1402-1407, 1997.

27. Kang YJ, Park HJ, Chung HJ, et al: Wnt/ $\beta$-catenin signaling mediates the antitumor activity of magnolol in colorectal cancer cells. Mol Pharmacol 82: 168-177, 2012.

28. Bishnupuri KS, Sainathan SK, Bishnupuri K, et al: Reg4-induced mitogenesis involves Akt-GSK3 $\beta-\beta$-Catenin-TCF-4 signaling in human colorectal cancer. Mol Carcinog 53 (Suppl 1): E169-E180, 2014. 